\title{
Outcomes of Persistently Active Neovascular Age-Related Macular Degeneration Treated with VEGF Inhibitors: Observational Study data.
}

Daniel Barthelmes ${ }^{1,9}$, Richard Walton ${ }^{1}$, Anna E Campain ${ }^{1}$, Judy M Simpson ${ }^{2}$, Jennifer J Arnold $^{3}$, Ian L McAllister ${ }^{4}$, Robyn H Guymer ${ }^{5}$, Alex P Hunyor ${ }^{1,6}$, Rohan W Essex ${ }^{7}$,

Nigel Morlet ${ }^{8}$, Mark C Gillies ${ }^{1}$ for the Fight Retinal Blindness! Project Investigators.

Supported by a grant from the Eye Foundation (2007-2009) and a grant from the National Health and Medical Research Council, Canberra, Australia (NHRMC 20101012). The authors state they have no conflicts of interest to declare. Mark Gillies is a Sydney Medical School Foundation Fellow. He and Robyn Guymer are supported by NHMRC practitioner fellowships. Daniel Barthelmes was supported by the Walter and Gertud Siegenthaler Foundation, Zurich, Switzerland and the Swiss National Foundation, Geneva.

1 The Save Sight Institute, Sydney Medical School, University of Sydney, Australia 2 Sydney School of Public Health, University of Sydney, Australia

3 Marsden Eye Specialists, Parramatta, NSW, Australia

4 The Lions Eye Institute, Perth, WA, Australia

5, Center for Eye Research Australia, University of Melbourne, Royal Victorian Eye and Ear Hospital, Australia

6 Retina Associates, Chatswood, NSW, Australia

7 Department of Ophthalmology, Canberra Hospital, Garran, ACT, Australia

8 University of Western Australia Department of Population Health, Perth, WA, Australia

9 Department of Ophthalmology, University Hospital Zurich, University of Zurich, Zurich, Switzerland 
Corresponding author: Professor Mark Gillies, Save Sight Institute, South Block, 8 Macquarie St. Sydney 2001 NSW, Australia. Email: mark.gillies@ sydney.edu.au Phone: +61 412060313

\section{Key words}

Patient outcome registry

Age-related macular degeneration

Post marketing observational study

Vascular endothelial growth factor inhibitors

Word count 2750 


\section{ABSTRACT}

Aim: To describe outcomes of eyes with wet AMD subdivided by lesion activity in a large multicenter cohort study.

Methods: Treatment-naïve eyes with sub-foveal choroidal neovascularization receiving anti-VEGF therapy enrolled in the Fight Retinal Blindness observational study were included. Lesions were graded at each visit as active if there was intraretinal or subretinal fluid attributable to leak from CNV lesion, or fresh hemorrhage. Eyes were divided into 4 groups based the proportion of visits each eye was graded as active during the first 12 months of treatment (Persistent, High, Moderate and Low activity).

Results: 655 eyes were included. Similar mean VA changes compared with baseline were observed in all 4 groups at 12 months $(+6.8,+8.3,+6.2$ and +5.5 letters for the Low, Moderate, High and Persistent groups respectively; $p<0.001$ for each group). The mean number of injections given increased only modestly in groups with more active lesions $(7.6,7.9,8.4,8.3$ respectively, $\mathrm{P}=0.015)$. Occult and minimally classic lesions were more frequent in the more active groups $(\mathrm{P}=0.024)$.

Conclusion: Persistent activity of neovascular lesions during 12 months after starting intravitreal therapy was not associated with worse visual outcomes in this observational study of AMD. 


\section{INTRODUCTION}

Despite the remarkable efficacy of Vascular Endothelial Growth Factor (VEGF) inhibitors for neovascular Age-related Macular Degeneration (wet AMD) ${ }^{1-3}$, there is still no consensus on how they are used most effectively. Monthly, pro re nata (PRN) 4 and "treat and extend" 5 are commonly used treatment regimens for wet AMD. An underlying principle of all treatments is that lesions with evidence of activity warrant further treatment ${ }^{6}$.

One of the leading indicators of persistent activity of choroidal neovascularization (CNV) is the presence of sub- or intra-retinal fluid. Previous experience with other conditions, particularly idiopathic central serous chorioretinopathy, suggests that the presence of subretinal fluid is eventually associated with progressive loss of vision which is thought to be secondary to the detachment of neuroretinal tissue from the retinal pigment epithelium ${ }^{7}$. Similarly, photoreceptor apoptosis has been described in rhegmatogenous retinal detachments in humans and animal models ${ }^{89}$. Persistent intraretinal fluid accumulation - typically seen in macular edema such as in uveitis or post-cataract surgery - has been proposed to result in lasting damage to retinal cells, eventually leading to fibrosis and atrophy of the neuroretinal tissue, ${ }^{10}$ thereby damaging vision irreversibly.

Persistently active CNVs, as evidenced by intra- or subretinal fluid, in eyes with AMD that are receiving regular treatment with anti-VEGF agents are commonly found in clinical practice. In the Comparison of AMD Treatment Trials (CATT) study, for example, the proportion of eyes with sub- or intra-retinal fluid ranged from $86.1 \%$ in the bevacizumab (Avastin) as needed group to $54.5 \%$ in the ranibizumab (Lucentis) monthly group after 2 years of treatment ${ }^{2}$. Strategies that have been proposed for eyes with persistent activity despite 4 weekly anti-VEGF therapy include 
injection of larger doses ${ }^{11} 12$, 2-weekly injections ${ }^{13}$ or combination with other agents ${ }^{14}$ ${ }^{15}$. Few data are available on the course of such lesions, however, to determine if these maneuvers are necessary.

Since are few good data are available from clinical trials in which independent Reading Centre adjudication of lesion activity has been correlated with outcomes, analysis of registry data can be performed to study this point in real world practice in which judgments are made by the treating clinician. Here we describe characteristics and clinical course of eyes of participants in an outcomes registry ${ }^{16}$ with wet AMD receiving injections of anti-VEGF drugs as a function of their CNV activity status. 


\section{METHODS}

\section{Design}

This observational study used anonymized longitudinal data from the FRB! Project's audit on eyes treated for wet AMD. The concepts of the FRB! system and the wet AMD audit have already been published ${ }^{16}{ }^{17}$. Briefly, anonymized data of patients treated for wet AMD were captured during routine clinical practice. Treatment decisions and visit schedules were made at the treating physician's discretion. This research project adheres to the Tenets of the Declaration of Helsinki. Ethics approval was obtained from the respective ethic committees by each participating center. Patients were given information about the project and were given the option to opt out of the audit in which their data were anonymized. Participating centers located in Australia, New Zealand and Switzerland contributed data.

\section{Patient selection and variables}

Treatment-naïve eyes with at least 12 months of follow-up were identified from the FRB! Project's wet AMD audit. Only eyes with at least 2 injections of ranibizumab and a maximum time between two consecutive visits of 150 days were included. In cases where both eyes from one participant were included, one was randomly deleted from the analysis set to ensure any inter-eye correlation would not bias estimates. Variables analyzed included: demographics (age, gender), visual acuity (VA) at each visit, lesion type (predominantly classic [PC], minimally classic [MC] and occult [OC]) and greatest linear dimension (GLD) of the neovascular lesion in $\mu \mathrm{m}$ identified by fundus fluorescein angiography, treatment at each visit and lesion status (active/inactive). Investigators were asked to enter whichever VA reading was best: uncorrected, corrected, or pinhole. VA scores were expressed as the number of letters 
read on a Logarithm of the Minimum Angle of Resolution chart. Lesion types were graded by individual contributors without reference to a reading center. The index visit was defined as the visit when treatment for wet AMD was commenced ${ }^{1617}$. While demographic and clinical characteristics were recorded at the index visit, only date, VA, treatment type, lesion activity and ocular side effects were recorded at follow-up visits.

Lesion activity status was graded by the treating physician based on funduscopy, optical coherence tomography imaging or fluorescein angiography alone or in combination at each visit. All ophthalmologists participating in this study agreed with the following statement: "Lesions were graded as active if there were features such as sub- or intra-retinal fluid, or new hemorrhage, that suggested that the CNV lesion was active".

\section{Primary outcome}

The primary outcome was change of VA in $\log$ MAR letters 12 months after the index visit within each of the four groups. For each eye the proportion of times over the 12 months of treatment at which the lesion was graded "active" was calculated. Four groups were formed and ranked in order of activity: "Persistent", "High", "Moderate" and "Low". Persistent activity was defined as activity at all visits. The cut points to form the other 3 groups were chosen to be at activity levels which would divide the remaining eyes into equally sized groups. 


\section{Secondary outcomes}

Secondary outcomes included the number of injections received during 12 months and reported adverse events.

\section{Statistics}

Descriptive statistics for continuous variables included mean, median and first and third quartiles (Q1 \& Q3). Where appropriate, continuous data were summarized with boxplots where the whisker length is either 1.5 times the interquartile range or the most extreme value (whichever is smaller). Categorical variables were summarized as percentages; any eyes with missing data were excluded from the denominator and formal comparisons were made with the chi-squared test.

An ordered logistic regression model ${ }^{18}$ was fitted to the data with age, index VA, lesion type and GLD as predictor variables for the ordinal activity group variable. Twelve-month within group change in VA outcomes were measured with the paired ttest. A LOESS regression ${ }^{19}$ was fitted to the 12-month follow-up data to elucidate the group longitudinal response profiles. All analyses were performed with R version $3.0 .0^{20}$ 


\section{RESULTS}

Twenty-seven ophthalmologists contributed data on 837 eyes with index visits between January 2007 and December 2011. Of the responding doctors, 70\% confirmed that they had used a "treat and extend" treatment regiment, as of 2011. The second most common treatment regiment (20\%) was a combination of "treat and extend" and "PRN". No doctors reported a completely PRN approach. One hundred and eighty two paired eyes (22\%) were randomly removed from the analysis set. Approximately $30 \%(n=196)$ of all available eyes were consistently graded active over 12 months' treatment, these formed the Persistent activity group (Table 1). Eyes classified as active for between $58 \%$ and $99 \%$ of the time formed the High activity group ( $\mathrm{n}=152,23 \%)$, those active between $27 \%$ and $57 \%$ formed the Moderate activity group ( $n=154,24 \%)$ and the remainder formed the Low activity group $(n=153,23 \%)$.

\section{Index visit data}

Mean patient age was similar across groups with an overall mean of 79.4 years, as was the proportion of females (overall 61.4\%) (Table 1). Mean index visual acuity was remarkably similar amongst the four groups (overall mean 54.9). The distribution of lesion types varied significantly across the four groups $\left(\mathrm{P}=0.02 ; \chi^{2}=23.5,12 \mathrm{df}\right)$. OC and MC lesions were increasingly frequent in the more active groups (Table 1). There was a small but significant trend of increasing activity with increasing GLD (linear correlation $=0.17,95 \% \mathrm{CI}: 0.09$ to 0.26$)$.

The observed differences in mean GLD per group may be a result of the different lesion type makeup of each group (Table 1). In order to further examine the relative associations of lesion type and GLD to lesion activity independent of one another, an ordered logistic regression model was fitted to the data. Results indicated that relative 
to the PC lesion type both OC (Odds ratio 1.8; 95\%CI 1.2 to 2.7) and MC (Odds ratio $2.3 ; 95 \%$ CI 1.4 to 3.8 ) had a significantly greater association with increased activity independent of lesion size. Lesion size was not significantly associated with increased activity independent of lesion type.

Table 1. Demographic and clinical characteristics at the index visit, by activity group.

\begin{tabular}{|c|c|c|c|c|c|}
\hline & $\begin{array}{c}\text { Low } \\
(0 \%-26 \%)\end{array}$ & $\begin{array}{c}\text { Moderate } \\
(27 \%-57 \%)\end{array}$ & $\begin{array}{l}\text { High } \\
(58 \%- \\
99 \%) \\
\end{array}$ & $\begin{array}{l}\text { Persistent } \\
(\mathbf{1 0 0 \%} \%)\end{array}$ & $\begin{array}{l}\text { Total / } \\
\text { overall }\end{array}$ \\
\hline Age, mean $\left(\mathrm{Q}_{1}, \mathrm{Q}_{3}\right)$ & $\begin{array}{l}80.1(76, \\
\text { oะl }\end{array}$ & $78.7(74,83)$ & $\begin{array}{l}79.3(76, \\
\text { ол }\end{array}$ & $78.5(74,83)$ & $79.4(75,84)$ \\
\hline$\%$ Female & $64 \%$ & $62 \%$ & $60 \%$ & $59 \%$ & $61 \%$ \\
\hline $\mathrm{VA}$, mean $\left(\mathrm{Q}_{1}, \mathrm{Q}_{3}\right)$ & $\begin{array}{l}55.8(47, \\
68)\end{array}$ & $53.7(45,69)$ & $\begin{array}{l}54.0(45, \\
65)\end{array}$ & $54.0(45,65)$ & $54.9(45,68)$ \\
\hline $\begin{array}{l}\text { GLD, median } \\
\left(\mathrm{Q}_{1}, \mathrm{Q}_{3}\right)\end{array}$ & $\begin{array}{c}1500 \\
(900,2210)\end{array}$ & $\begin{array}{c}2000 \\
(1200,3000)\end{array}$ & $\begin{array}{r}2100 \\
(1500 \\
3190)\end{array}$ & $\begin{array}{c}2170 \\
(1450,3210)\end{array}$ & $\begin{array}{c}2000 \\
(1250,3000)\end{array}$ \\
\hline \multicolumn{6}{|l|}{ Lesion Type n (\%) } \\
\hline Occult & $58(19 \%)$ & $71(24 \%)$ & $79(26 \%)$ & $93(31 \%)$ & $301(100 \%)$ \\
\hline Minimally Classic & $20(18 \%)$ & $25(22 \%)$ & $25(22 \%)$ & $43(38 \%)$ & $113(100 \%)$ \\
\hline $\begin{array}{l}\text { Predominant } \\
\text { Classic }\end{array}$ & $34(31 \%)$ & $30(27 \%)$ & $24(22 \%)$ & $22(20 \%)$ & $110(100 \%)$ \\
\hline Other & $9(23 \%)$ & $7(18 \%)$ & $8(21 \%)$ & $15(38 \%)$ & $39(100 \%)$ \\
\hline Unclassified & $32(35 \%)$ & $21(23 \%)$ & $16(17 \%)$ & $23(25 \%)$ & $92(100 \%)$ \\
\hline Total & $153(23 \%)$ & $154(24 \%)$ & $152(23 \%)$ & $196(30 \%)$ & $655(100 \%)$ \\
\hline
\end{tabular}

Primary outcome - change in VA at 12 months after index visit

The mean index VA was similar for the 4 groups. Similar mean visual acuity improvements were observed in all groups over the course of 12 months' treatment (Loess lines, Fig 1) with clinically relevant (>5 logMAR letters) improvements observed at 12 months of 6.8, 8.3, 6.2 and 5.5 letters for the Low, Moderate, High and Persistent groups respectively (Table 2). Each group had statistically significantly improved VA at 12 months compared with the index visit $(\mathrm{p}<0.001)$.

\section{Secondary outcomes -Treatment intensity}

Early treatment, as measured by time to the 3rd injection in each group was consistent (Table 2). The mean number of intravitreal injections administered over 12 months 
increased modestly with increasing lesion activity $(\mathrm{P}=0.0151$, Poisson regression;

Table 2). Further examination stratified by time revealed a pattern of change in injection intensity that was most noticeable in the Low activity group over time (Panel A, Fig 2). Mean injections per year was 5.2 for eyes in the Low activity group which began treatment in 2007 increasing to 8.6 in 2010 and 7.5 in $2011(\mathrm{P}=0.007$, Poisson regression).

Twelve-month improvements in VA did not change markedly over time (2007-2011) in any group (Fig 3).

Table 2 . Outcomes at 12 months by activity group

\begin{tabular}{lcccc}
\hline & $\begin{array}{c}\text { Low } \\
(\mathbf{0 \%}-\mathbf{2 6 \%})\end{array}$ & $\begin{array}{c}\text { Moderate } \\
(\mathbf{2 7 \%}-\mathbf{5 6 \%})\end{array}$ & $\begin{array}{c}\text { High } \\
(\mathbf{5 7 \%}-\mathbf{9 9 \%})\end{array}$ & $\begin{array}{c}\text { Persistent } \\
(\mathbf{1 0 0 \%})\end{array}$ \\
\hline Days to 3 $^{\text {rd }}$ injection, med $\left(\mathbf{Q}_{1}, \mathbf{Q}_{3}\right)$ & $63(56,77)$ & $64(58,75)$ & $65(58,77)$ & $64(58,77)$ \\
$\mathbf{1 2}$ month \# inj, mean $\left(\mathbf{Q}_{\mathbf{1}}, \mathbf{Q}_{3}\right)$ & $7.7(6,9)$ & $8.0(7,10)$ & $8.5(7,10)$ & $8.3(7,9)$ \\
$\mathbf{1 2}$ month VA, mean $\left(\mathbf{Q}_{1}, \mathbf{Q}_{3}\right)$ & $62.6(55,75)$ & $62.0(55,75)$ & $60.2(52,74)$ & $59.5(50,73)$ \\
$\mathbf{0 - 1 2}$ month mean VA change $(\mathbf{9 5 \%}$ & $6.8(4.0$ to 9.6$)$ & $8.3(5.8$ to 10.7$)$ & $6.2(3.5$ to 8.6$)$ & $5.5(3.2$ to 7.7$)$ \\
$\mathbf{C I})$ & & & & \\
\hline
\end{tabular}

Secondary outcomes - Safety

Adverse events reported during 12 months' treatment are shown in Table 3. All 4 instances of Retinal Pigment Epithelium tear occurred in the High and Persistent activity groups. We did not attempt to track systemic adverse events since we do not believe that this can be done accurately in registries such as these. ${ }^{26}$

Table 3. Injections and reported adverse events during 12 months' treatment by activity group.

\begin{tabular}{lccccc}
\hline & Low & Moderate & High & Persistent & Total \\
\hline Injection count & 1172 & 1225 & 1287 & 1621 & 5305 \\
& & & & & \\
Retinal detachment & 0 & 0 & 1 & 0 & 1 \\
Non-infectious endophthalmitis & 0 & 0 & 2 & 0 & 2 \\
Infectious endophthalmitis & 1 & 0 & 0 & 1 & 2 \\
Retinal Pigment Epithelium tear & 0 & 0 & 1 & 3 & 4 \\
\hline Total & $\mathbf{1}$ & $\mathbf{0}$ & $\mathbf{4}$ & $\mathbf{4}$ & $\mathbf{9}$ \\
\hline
\end{tabular}




\section{Discussion}

We have analyzed outcomes of eyes treated for neovascular AMD according to the surgeon's grading of neovascular lesion activity over 12 months after commencing treatment with intravitreal ranibizumab. Interestingly, eyes with lesions that were graded by the treating surgeon as being active at most visits had similar 12-month VA outcomes to those with less active lesions. Chronically active lesions were generally larger and more likely to be occult in nature, yet all activity groups studied showed a clear improvement in mean VA over 12 months. Ocular adverse events were uncommon and similar to data published previously ${ }^{21}$.

The analysis of observational study data has strengths and weaknesses compared with data from RCTs, which are the source of information upon which clinical decisions are usually made, at least in this field. Observational studies lack a strict protocol for re-treatment, with potential for considerable variation in treatment practices among the 27 clinicians involved. All 27 participating ophthalmologists stated that they used a "treat and extend" treatment regimen. The advantage of observational studies is they tell us how treatments are given in routine practice, in this case how clinicians interpret lesion activity and the effect this has on number of injections required and the VA outcome.

Although it might be expected that eyes with chronically active lesions would have less favorable VA outcomes due to progressive structural damage of the outer retina, we did not find this. Outcomes were similar among the four groups ranked for degree of activity. One reason contributing to this may be the higher proportion of occult 
lesions in the more active groups, since it has been reported that untreated occult-only lesions have a more favorable outcome than lesions with classic components, ${ }^{21}$ possibly because they cause less structural damage of the neural retina. The CATT study reported that lesions with a classic component were likely to result in less favorable VA outcomes at 12 months. ${ }^{22}$

There were higher proportions of occult membranes in the more active groups. While this may seem counter-intuitive, occult membranes have not penetrated the Retinal Pigment Epithelium $^{23}$, the site of the outer blood-retinal barrier, whereas most classic neovascular complexes have ${ }^{24}$. Thus an intravitreally injected drug may reach classic neovascularization at higher levels than it does for occult membranes, which may therefore be less responsive to the same treatment. Further research may be warranted to determine whether higher doses of VEGF inhibitors are more effective for occult lesions.

Few studies have used lesion activity as assessed by the treating physician as an outcome. Recording this grading provides information on how clinicians reach treatment decisions. While it is not possible to impose standardized treatment regimens in observational studies, we only included data from surgeons who agreed with the following statement: "Lesions were graded as active if there were features such as sub- or intra-retinal fluid, or new hemorrhage, that suggested that the CNV lesion was active." Therefore, the stratification of patients according to lesion activity is likely to have been consistent. The variation between a Reading Centre's and an injecting clinician's interpretation of whether a lesion is active or not is unlikely to be 
large. If there is a discrepancy between the two, the judgment of the clinician is of more practical relevance. The significantly different proportions of lesion types amongst the four groups, with increased prevalence of occult lesions associated with an increased duration of lesion activity on treatment, also suggests that the four strata of lesion activity were different.

A surprising observation was that eyes in all four groups received similar numbers of injections over the first 12 months. In the first year of the study (2007) the number of injections appeared to be lower in the low activity group. This may reflect the evolving understanding the ophthalmic community had at that time regarding the importance of adequate treatment, particularly the risk of under-treatment, as presented in the Phase IIIb, multicenter, randomized, double-masked, sham injectioncontrolled study of the efficacy and safety of ranibizumab in subjects with subfoveal $\mathrm{CNV}$ with or without classic CNV secondary to AMD (PIER) study ${ }^{25}$. It also may reflect a growing acceptance by doctors of some degree of lesion activity, for example a small amount of subretinal fluid in the outer macula of patients undergoing intravitreal therapy if the visual acuity is stable and patients are reluctant to undergo more intensive treatment. Furthermore, the number of injections did not seem to have had an impact on the VA outcome - suggesting that clinicians may have been guided more by VA results than by lesion activity. At least in the patient cohort studied, persistence of CNV activity was not associated with an unfavorable outcome within 12 months after commencing treatment. 
In conclusion, we found that lesion activity as assessed by the treating physician had less effect on visual acuity outcomes from intravitreal therapy for neovascular AMD than expected. It is important to note that the data presented were collected at a time when clinicians generally agreed that the goal of treatment was to render lesions inactive. Treating persistently active lesions less aggressively might result in inferior outcomes. If our results are replicated by other studies, perhaps there may be less emphasis on using higher doses or treating persistently active lesions more frequently. Further research is warranted to determine outcomes when physicians place less emphasis on lesion activity as an indication for treatment. 
Figure 1 Legend

Fig 1: Longitudinal profile plots of all eyes over 12 months by activity group (A: Low activity; B Moderate activity; C High activity; D Persistent activity). Each dot represents a measurement of visual acuity during 12 months' treatment. A red dot indicates the eye was graded "active" while a green dot represents "inactive" status. The Loess line fitted to the data elucidates group changes in VA over time.

Figure 2 Legend:

Fig 2: Boxplot of 12-month injection counts per eye by year and activity group (A: Low activity; B Moderate activity; C High activity; D Persistent activity).

Figure 2 Legend:

Fig 2: Boxplot of 12-month injection counts per eye by year and activity group (A: Low activity; B Moderate activity; C High activity; D Persistent activity). 


\section{References}

1. Brown DM, Kaiser PK, Michels M, et al. Ranibizumab versus verteporfin for neovascular age-related macular degeneration. The New England journal of medicine 2006;355:1432-44

2. Martin DF, Maguire MG, Fine SL, et al. Ranibizumab and Bevacizumab for Treatment of Neovascular Age-Related Macular Degeneration: Two-Year Results. Ophthalmology 2012;119:1388-98

3. Rosenfeld PJ, Brown DM, Heier JS, et al. Ranibizumab for neovascular age-related macular degeneration. The New England journal of medicine 2006;355:141931

4. Lalwani GA, Rosenfeld PJ, Fung AE, et al. A variable-dosing regimen with intravitreal ranibizumab for neovascular age-related macular degeneration: year 2 of the PrONTO Study. American journal of ophthalmology 2009; 148:43-58 e1

5. Gupta OP, Shienbaum G, Patel AH, Fecarotta C, Kaiser RS, Regillo CD. A treat and extend regimen using ranibizumab for neovascular age-related macular degeneration clinical and economic impact. Ophthalmology 2010;117:2134-40

6. Kovach JL, Schwartz SG, Flynn HW, Jr., Scott IU. Anti-VEGF Treatment Strategies for Wet AMD. Journal of ophthalmology 2012;2012:786870

7. Castro-Correia J, Coutinho MF, Rosas V, Maia J. Long-term follow-up of central serous retinopathy in 150 patients. Documenta ophthalmologica. Advances in ophthalmology 1992;81:379-86

8. Hisatomi T, Sakamoto T, Murata T, et al. Relocalization of apoptosis-inducing factor in photoreceptor apoptosis induced by retinal detachment in vivo. The American journal of pathology 2001;158:1271-8

9. Ranty ML, Carpentier S, Cournot M, et al. Ceramide production associated with retinal apoptosis after retinal detachment. Graefe's archive for clinical and experimental ophthalmology $=$ Albrecht von Graefes Archiv fur klinische und experimentelle Ophthalmologie 2009;247:215-24

10. Malinowski SM, Pulido JS, Folk JC. Long-term visual outcome and complications associated with pars planitis. Ophthalmology 1993;100:818-24; discussion 25

11. Brown DM, Chen E, Mariani A, Major JC, Jr. Super-dose Anti-VEGF (SAVE) Trial: $2.0 \mathrm{mg}$ Intravitreal Ranibizumab for Recalcitrant Neovascular Macular Degeneration-Primary End Point. Ophthalmology 2013;120:349-54

12. Wykoff CC, Brown DM, Chen E, et al. SAVE (Super-dose anti-VEGF) trial: 2.0 $\mathrm{mg}$ ranibizumab for recalcitrant neovascular age-related macular degeneration: 1-year results. Ophthalmic surgery, lasers \& imaging retina 2013;44:121-6

13. Stewart MW, Rosenfeld PJ, Penha FM, et al. Pharmacokinetic rationale for dosing every 2 weeks versus 4 weeks with intravitreal ranibizumab, bevacizumab, and aflibercept (vascular endothelial growth factor Trap-eye). Retina 2012;32:434-57

14. Williams PD, Callanan D, Solley W, Avery RL, Pieramici DJ, Aaberg T. A prospective pilot study comparing combined intravitreal ranibizumab and halffluence photodynamic therapy with ranibizumab monotherapy in the treatment of neovascular age-related macular degeneration. Clin Ophthalmol 2012;6:1519-25

15. Yoshizawa C, Saito W, Hirose S, Kitamei H, Noda K, Ishida S. Photodynamic therapy combined with intravitreal bevacizumab and sub-tenon triamcinolone 
acetonide injections for age-related macular degeneration. Japanese journal of ophthalmology 2013;57:68-73

16. Gillies MC, Walton R, Liong J, et al. EFFICIENT CAPTURE OF HIGHQUALITY DATA ON OUTCOMES OF TREATMENT FOR MACULAR DISEASES: The Fight Retinal Blindness! Project. Retina 2014;34:188-95

17. Gillies MC, Walton R, Simpson JM, et al. Prospective audit of exudative agerelated macular degeneration: 12-month outcomes in treatment-naive eyes. Investigative ophthalmology \& visual science 2013;54:5754-60

18. Agresti A. An Introduction to Categorical Data Analysis. New York: John Wiley \& Sons, Inc, 1996.

19. Cleveland WS, Grosse E, Shyu WM. Local regression models. Statistical Models in S: Wadsworth \& Brooks/Cole, 1992.

20. R: A Language and Environment for Statistical Computing. Vienna, Austria: Foundation for Statistical Computing.

21. Occult choroidal neovascularization. Influence on visual outcome in patients with age-related macular degeneration. Macular Photocoagulation Study Group. Archives of ophthalmology 1996;114:400-12

22. Ying GS, Huang J, Maguire MG, et al. Baseline Predictors for One-Year Visual Outcomes with Ranibizumab or Bevacizumab for Neovascular Age-related Macular Degeneration. Ophthalmology 2013;120:122-29

23. Subfoveal neovascular lesions in age-related macular degeneration. Guidelines for evaluation and treatment in the macular photocoagulation study. Macular Photocoagulation Study Group. Archives of ophthalmology 1991;109:1242-57

24. Gass JD. Pathogenesis of disciform detachment of the neuroepithelium. American journal of ophthalmology 1967;63:Suppl:1-139

25. Brown DM, Tuomi L, Shapiro H. Anatomical measures as predictors of visual outcomes in ranibizumab-treated eyes with neovascular age-related macular degeneration. Retina 2013;33:23-34 
Figure 1 Legend

Fig 1: Longitudinal profile plots of all eyes over 12 months by activity group (A: Low activity; B Moderate activity; C High activity; D Persistent activity). Each dot represents a measurement of visual acuity during 12 months' treatment. A red dot indicates the eye was graded "active" while a green dot represents "inactive" status. The Loess line fitted to the data elucidates group changes in VA over time.
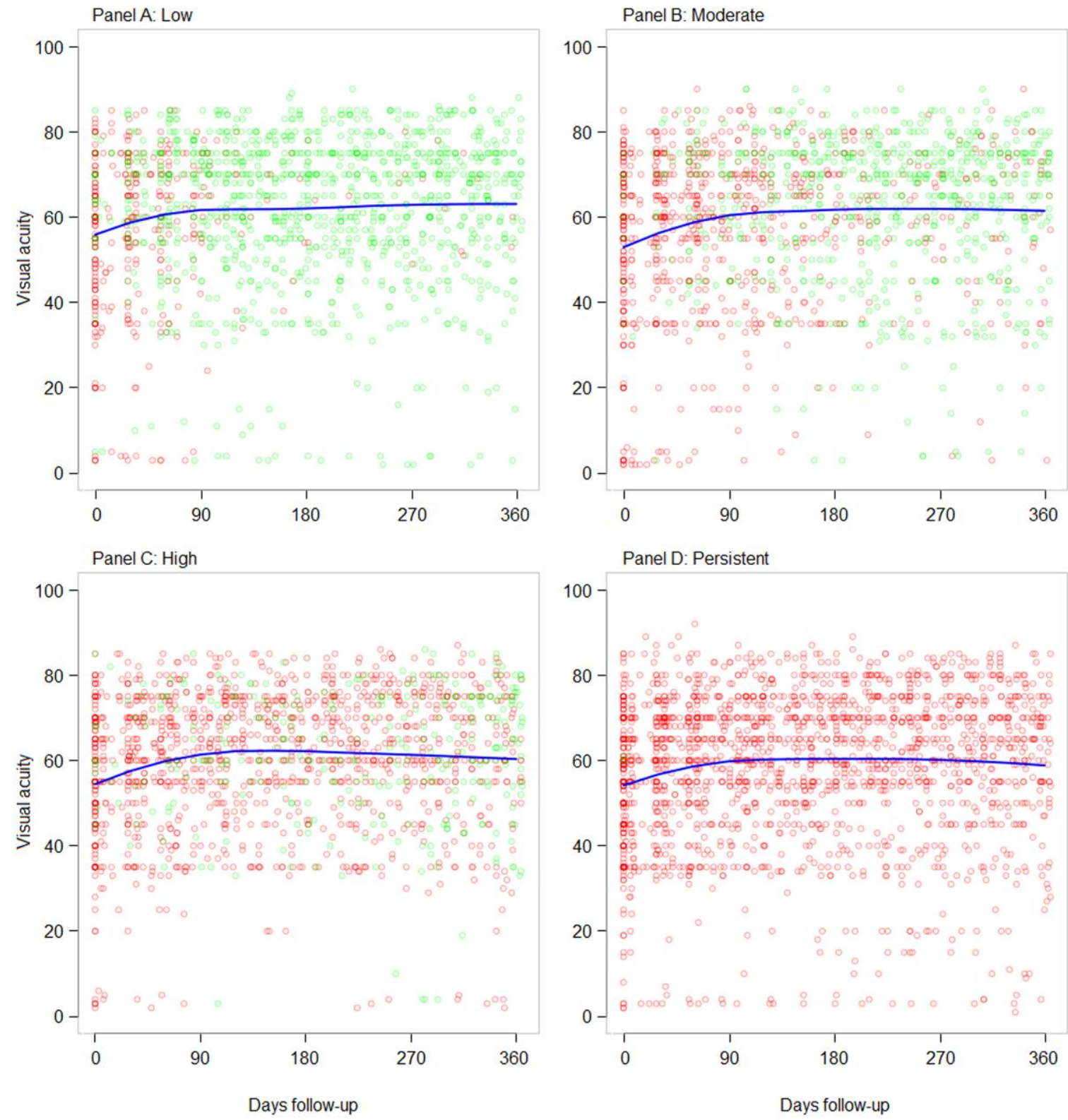
Figure 2 Legend:

Fig 2: Boxplot of 12-month injection counts per eye by year and activity group (A: Low activity; B Moderate activity; C High activity; D Persistent activity).
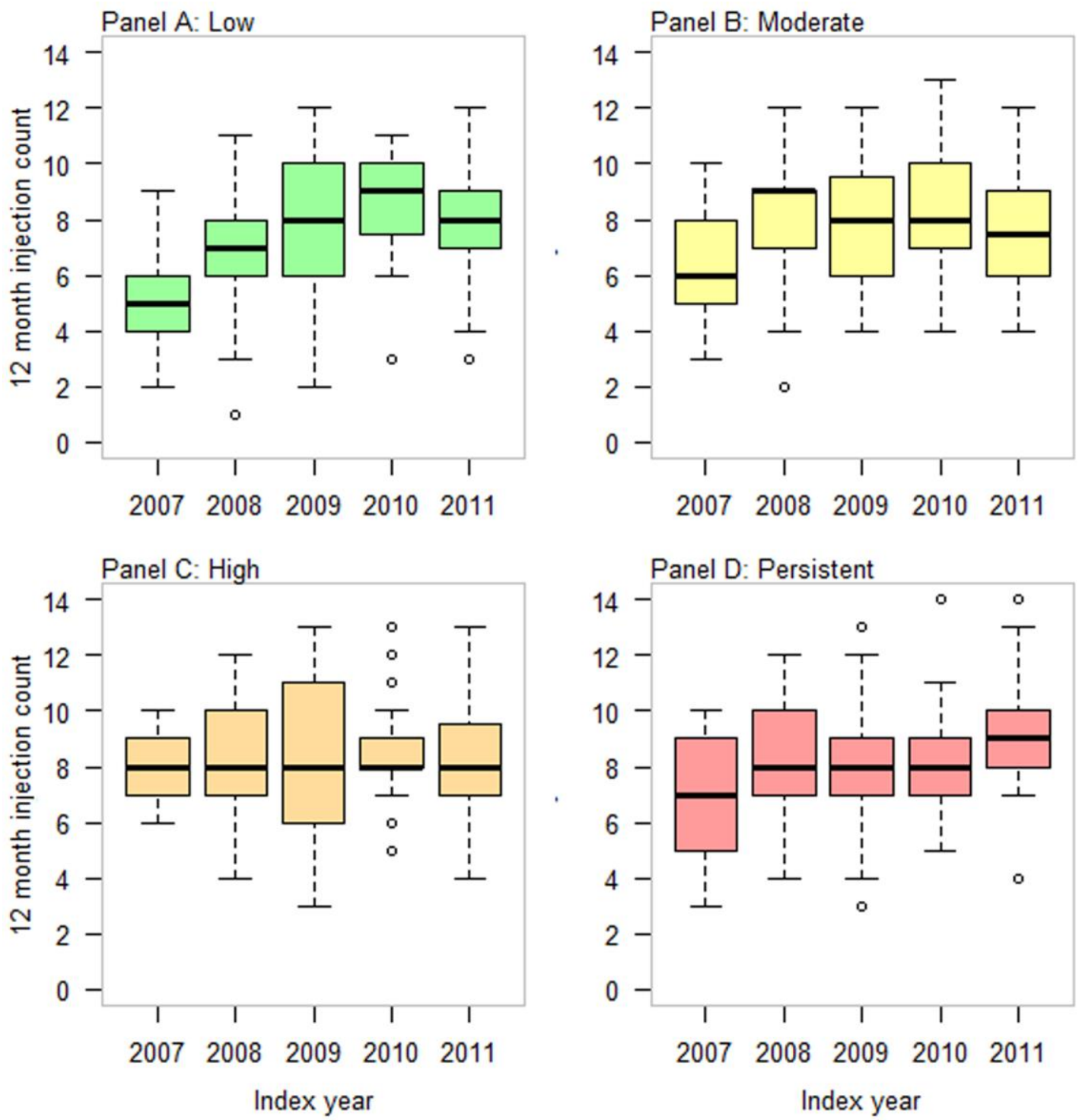
Figure 3 Legend:

Fig 3: Boxplot of 12-month change in VA by year and activity group (A: Low activity; B Moderate activity; C High activity; D Persistent activity).
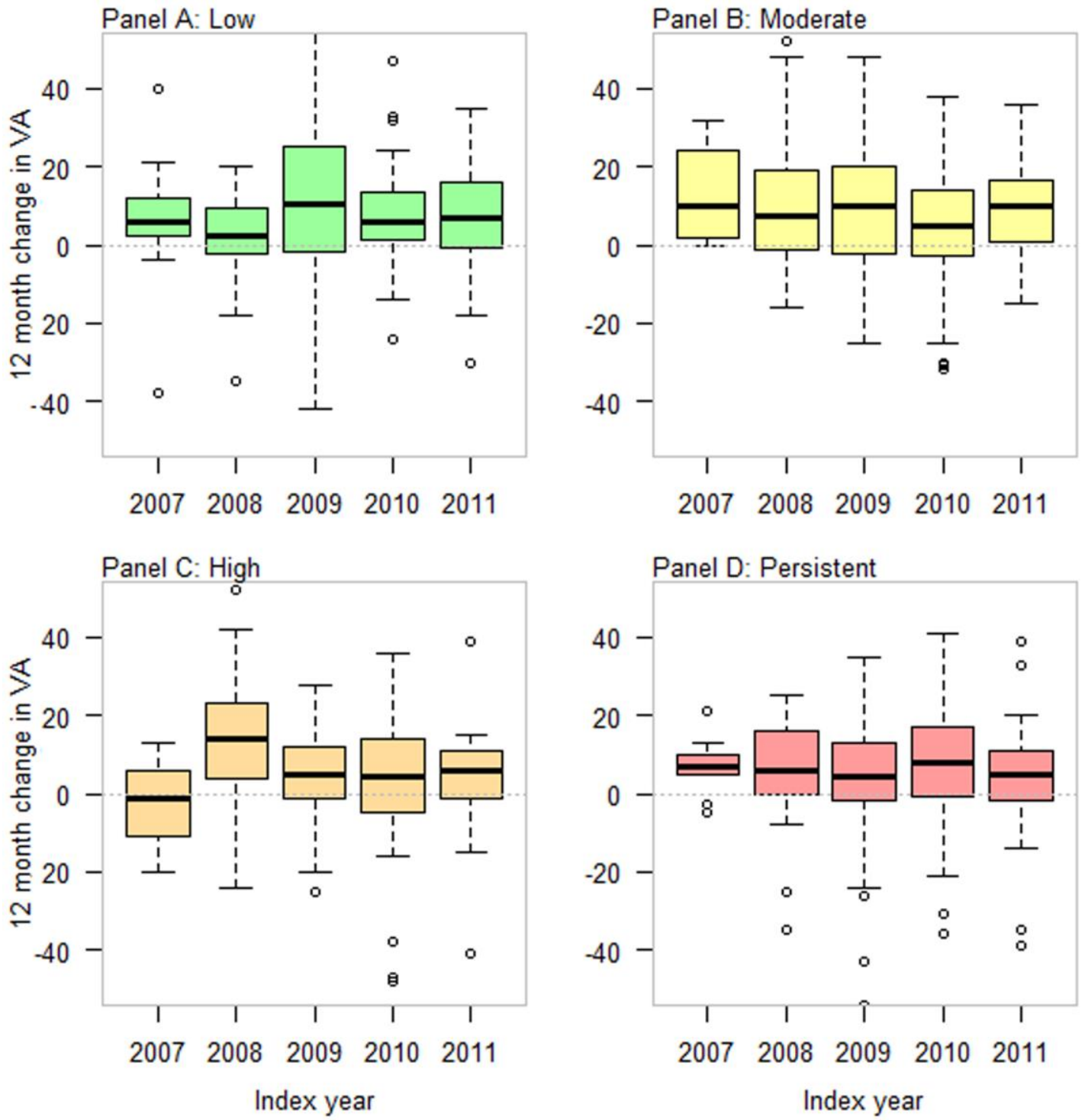
Table 1. Demographic and clinical characteristics at the index visit, by activity group.

\begin{tabular}{lccccc}
\hline & $\begin{array}{c}\text { Low } \\
\mathbf{( 0 \% - 2 6 \% )}\end{array}$ & $\begin{array}{c}\text { Moderate } \\
\mathbf{( 2 7 \% - 5 7 \% )}\end{array}$ & $\begin{array}{c}\text { High } \\
\mathbf{( 5 8 \% - 9 9 \% )}\end{array}$ & $\begin{array}{c}\text { Persistent } \\
\mathbf{( 1 0 0 \% )}\end{array}$ & Total/ overall \\
\hline Age, mean $\left(\mathrm{Q}_{1}, \mathrm{Q}_{3}\right)$ & $80.1(76,85)$ & $78.7(74,83)$ & $79.3(76,84)$ & $78.5(74,83)$ & $79.4(75,84)$ \\
$\%$ Female & $64 \%$ & $62 \%$ & $60 \%$ & $59 \%$ & $61 \%$ \\
VA, mean $\left(\mathrm{Q}_{1}, \mathrm{Q}_{3}\right)$ & $55.8(47,68)$ & $53.7(45,69)$ & $54.0(45,65)$ & $54.0(45,65)$ & $54.9(45,68)$ \\
GLD, median & 1500 & 2000 & 2100 & 2170 & 2000 \\
$\quad\left(\mathrm{Q}_{1}, \mathrm{Q}_{3}\right)$ & $(900,2210)$ & $(1200,3000)$ & $(1500,3190)$ & $(1450,3210)$ & $(1250,3000)$ \\
Lesion Type n $(\%)$ & & & & \\
$\quad$ Occult & $58(19 \%)$ & $71(24 \%)$ & $79(26 \%)$ & $93(31 \%)$ & $301(100 \%)$ \\
$\quad$ Minimally Classic & $20(18 \%)$ & $25(22 \%)$ & $25(22 \%)$ & $43(38 \%)$ & $113(100 \%)$ \\
$\quad$ Predominant Classic & $34(31 \%)$ & $30(27 \%)$ & $24(22 \%)$ & $22(20 \%)$ & $110(100 \%)$ \\
$\quad$ Other & $9(23 \%)$ & $7(18 \%)$ & $8(21 \%)$ & $15(38 \%)$ & $39(100 \%)$ \\
$\quad$ Unclassified & $32(35 \%)$ & $21(23 \%)$ & $16(17 \%)$ & $23(25 \%)$ & $92(100 \%)$ \\
\hline$\quad$ Total & $153(23 \%)$ & $154(24 \%)$ & $152(23 \%)$ & $196(30 \%)$ & $655(100 \%)$ \\
\hline
\end{tabular}


Table 2 . Outcomes at 12 months by activity group

\begin{tabular}{lcccc}
\hline & $\begin{array}{c}\text { Low } \\
(\mathbf{0 \%}-\mathbf{2 6} \%)\end{array}$ & $\begin{array}{c}\text { Moderate } \\
(\mathbf{2 7 \%}-\mathbf{5 6} \%)\end{array}$ & $\begin{array}{c}\text { High } \\
\mathbf{( 5 7 \% - 9 9 \% )}\end{array}$ & $\begin{array}{c}\text { Persistent } \\
(\mathbf{1 0 0 \%})\end{array}$ \\
\hline Days to 3 ${ }^{\text {rd }}$ injection, med $\left(\mathbf{Q}_{1}, \mathbf{Q}_{3}\right)$ & $63(56,77)$ & $64(58,75)$ & $65(58,77)$ & $64(58,77)$ \\
$\mathbf{1 2}$ month \# inj, mean $\left(\mathbf{Q}_{1}, \mathbf{Q}_{3}\right)$ & $7.7(6,9)$ & $8.0(7,10)$ & $8.5(7,10)$ & $8.3(7,9)$ \\
$\mathbf{1 2}$ month VA, mean $\left(\mathbf{Q}_{1}, \mathbf{Q}_{3}\right)$ & $62.6(55,75)$ & $62.0(55,75)$ & $60.2(52,74)$ & $59.5(50,73)$ \\
$\begin{array}{l}\mathbf{0 - 1 2} \text { month mean VA change }(\mathbf{9 5 \%} \\
\text { CI) }\end{array}$ & $6.8(4.0$ to 9.6$)$ & $8.3(5.8$ to 10.7$)$ & $6.2(3.5$ to 8.6$)$ & $5.5(3.2$ to 7.7$)$ \\
\hline
\end{tabular}


Table 3. Injections and reported adverse events during 12 months' treatment by activity group.

\begin{tabular}{lccccc}
\hline & Low & Moderate & High & Persistent & Total \\
\hline Injection count & 1172 & 1225 & 1287 & 1621 & 5305 \\
Retinal detachment & 0 & 0 & 1 & 0 & 1 \\
Non-infectious endophthalmitis & 0 & 0 & 2 & 0 & 2 \\
Infectious endophthalmitis & 1 & 0 & 0 & 1 & 2 \\
Retinal Pigment Epithelium tear & 0 & 0 & 1 & 3 & 4 \\
\hline Total & $\mathbf{1}$ & $\mathbf{0}$ & $\mathbf{4}$ & $\mathbf{4}$ & $\mathbf{9}$ \\
\hline
\end{tabular}

